\title{
Michel Foucault y la relación pastor-rebaño en las culturas griega y latina
}

\section{Michel Foucault and the relation shepherd-flock in Greek and Latin cultures}

\author{
Miguel OMAR Masci
}

Universidad Nacional de La Plata, La Plata, Argentina

\begin{abstract}
RESUMEN. Antes del siglo XVI, la palabra «gobernar», afirma Foucault, nunca aludió al gobierno de un Estado, de un territorio o una estructura política. La palabra «gobernar» siempre estuvo referida al gobierno de la gente, de los individuos, de las colectividades. La relación que entablaba el rey o Dios o jefe con su pueblo era del mismo tipo que la entablada por el pastor con su rebaño. De acuerdo con Foucault, ni en la cultura griega ni en la romana podemos encontrar este tipo de relación, dado que ésta sería propia del oriente precristiano y cristiano. Sin embargo, en este trabajo intentaremos mostrar que es posible rastrear dicha relación tanto en Homero como en Platón y en Virgilio.
\end{abstract}

Palabras clave: Ilíada, Agamenón, Eneida, Eneas, Platón, el tejedor.

\section{Introducción}

El término «gubernamentalidad» es una compleja noción que para Foucault encierra tres cuestiones: a) el conjunto de instituciones, procedimientos, análisis, reflexiones, cálculos y tácticas, que permiten ejercer un tipo de poder bien específico sobre la población; b) una tendencia fuertemente marcada en Occidente, que introdujo un tipo de poder que está por sobre la soberanía y la disciplina,
Abstract. Before the sixteenth century, the term «to govern», says Foucault, never has refered to goverment of a State, a territory, or a political structure. The term «to govern» always has been refered to goverment of people, persons or collectivities. The relation that God, king or leader founded with his people was in the same way as shepherd founded with his flock. In keeping with Foucault, neither in Greek culture nor in Latin culture we can find this relation. It would be proper of pre-Christian and Christian Orient. Howsoever, in this paper we show that is possible to trace this relation in Homer, Plato and Vergil.

Key words: Iliad, Agamemnon, Aeneid, Aeneas, Plato, weaver.

provocando el desarrollo de una serie de aparatos específicos de gobierno y una serie de saberes; c) el proceso mediante el cual el estado de justicia de la Edad Media, convertido en Estado administrativo durante los siglos XV y XVI, poco a poco se «gubernamentalizó» ${ }^{1}$.

Una de las cuestiones a tratar en el curso que el filósofo francés brindó durante el primer semestre de 1978 fue la de mostrar que la noción de gubernamentalidad tuvo su origen, primero, en el mo- 
delo arcaico de la pastoral cristiana; segundo, sobre la base de una técnica diplomático-militar; y por último en la policía. Dentro de esta ambiciosa empresa, nuestro objetivo, en cambio, será preciso y modesto. Antes de abordar el análisis de la pastoral cristiana, Foucault realiza un rastreo histórico de la nación del político como pastor de rebaños en las culturas griega y romana. En las páginas que siguen, intentaremos mostrar que su tesis de que la idea del político como pastor de rebaños no se encuentra en las mencionadas culturas es, al menos, difícil de sostener. Para ello, nuestro trabajo comenzará con la exposición de los argumentos de Foucault en favor de la tesis mencionada. Más tarde, realizaremos breves recorridos por unos pocos pasajes de la Ilíada y la Eneida, para culminar en Platón y la mitología presente en Critias, Leyes y Político, así como también las diferencias entre el pastor y el tejedor presentes en este último diálogo.

\section{El poder pastoral}

Antes de adoptar su significado político, a partir del siglo XVI, la palabra «gobernar» nunca aludió, refiere Foucault, al gobierno de un Estado, de un territorio o de una estructura política. La palabra «gobernar» siempre estuvo referida al gobierno de la gente, de los individuos, de las colectividades. Específicamente, la palabra abarcaba un campo semántico amplio: subsistencia material, alimentación, desplazamiento en el espacio, salvación de los individuos, prescripción, como también dominio sobre sí mismo y los otros, sobre el cuerpo y también sobre el alma; por último, también ha abarcado los procesos de comercio, como la circulación y el intercambio de un individuo y otro ${ }^{2}$. A partir de ello, Foucault realizará un análisis tendiente a demostrar que la idea de que a los que se gobierna son los hombres no es una idea que podamos encontrar en la cultura griega ni en la romana.

La primera obra clásica a la que Foucault hace referencia es Edipo rey, de Sófocles. En ésta, Foucault encuentra la metáfora del rey que tiene a la ciudad a su cargo, del mismo modo en que el piloto tiene a su cargo la nave, a la que debe salvar de los escollos y llevar a buen puerto. Todas las metáforas que asimilan al rey con el buen piloto y a la ciudad con la nave, pondrían de manifiesto, de acuerdo a Foucault, que lo que se gobierna es la ciudad. Los hombres se gobiernan pero de manera indirecta: en cuanto ellos también están embarcados en la nave ${ }^{3}$. La idea de un gobierno de los hombres debemos rastrearla, sostiene Foucault, primero en el Oriente precristiano y luego en el Oriente cristiano. En estos sitios la idea se revela de dos formas: como organización de un poder de tipo pastoral y como dirección de las conciencias, de las almas ${ }^{4}$. Por nuestra parte, acompañaremos a Foucault en la descripción y análisis de la primera de las formas en que la idea del gobierno de los hombres se manifiesta: el poder de tipo pastoral; pues intentar realizar lo propio con la segunda de las formas mencionadas en que tal idea se manifiesta excedería los límites de este trabajo.

La concepción del rey o dios o jefe como pastor del rebaño de los hombres es una idea que, según Foucault, frecuentemente podemos hallar en el Oriente mediterráneo: Egipto, Asiria y Mesopotamia, y sobremanera en los hebreos. En todos los casos, la premisa de la cual se parte, como ya aseveramos, es la de Dios como pastor de los hombres:

«si dios es el pastor de los hombres y el rey también lo es, este último es de alguna manera el pastor subalterno a quien aquél ha confiado el rebaño de los hombres y debe, al término de la jornada y en el anochecer de su reino, devolver a Dios el rebaño que se le ha entregado. El pastorado es un tipo de relación fundamen- 
tal entre Dios y los hombres, y el rey participa en cierto modo de esa estructura pastoral de la relación» 5 .

El tema del pastorado, desarrollado e intensificado por los hebreos, tiene la particularidad, advierte Foucault, de que la relación pastor-rebaño es fundamentalmente religiosa. Antes de presentar los rasgos fundamentales del pastorado, Foucault se encarga de remarcar que la idea de un dios o varios dioses conduciendo a los hombres, como un pastor o un mayoral harían con su rebaño, no es algo que se encuentre entre los griegos. Éstos podían atribuir una cierta intimidad de los dioses con la ciudad, pero de ninguna manera con las características formuladas. El dios griego fundaba la ciudad, indicaba su emplazamiento, construía las murallas, garantizando su solidez, daba un nombre al poblado y trasmitía sus consejos mediante el oráculo, pero no conducía a los hombres de la ciudad como un pastor a sus corderos.

Pues bien, examinemos las características que a juicio de Foucault presenta el pastorado. En primer lugar, el poder del pastor no es un poder que se ejerza sobre un territorio, sino sobre su rebaño, específicamente sobre un rebaño en movimiento. En otras palabras, el poder del pastor se ejerce sobre una multitud en movimiento: «El Dios griego se presenta, antes bien, sobre las murallas para defender la ciudad. El Dios hebreo aparece precisamente cuando se abandona la ciudad, a la salida de las murallas, y se comienza a seguir el camino a través de las praderas» ${ }^{6}$. En segundo lugar, el poder pastoral es un poder benévolo. Su función es hacer el bien; y hacer el bien significa obtener la salvación de su rebaño. El poder pastoral es fundamentalmente un poder de «cuidados»: cuida el rebaño, cuida los individuos, vela porque las ovejas no sufran, va a buscar a las extraviadas, cura a las heridas. En suma, el pastor está al servicio del rebaño, lo que implica que el poder pastoral en sí mismo es siempre un bien. Por último, Foucault destaca que el poder pastoral es un poder individualizador, y lo es en el siguiente sentido. El pastor dirige a todo el rebaño, pero lo hace bien sólo cuando ninguna de las ovejas se le escapa. El pastor hace todo por el conjunto del rebaño, pero también lo hace por cada una de sus ovejas: omnes et singulatim.

Resumiendo, el poder pastoral es un poder ejercido sobre una multiplicidad y no sobre un territorio; es un poder que guía hacia una meta, sirviendo de intermediario en el camino hacia ella; es un poder, en definitiva, finalista, y un poder que se refiere a todos y a cada uno a la vez y no a la unidad superior formada por el todo ${ }^{7}$.

\section{Platón, la gran excepción}

Foucault se ve obligado a alterar la rutina de su clase del 15 de febrero de 1978 para responder a ciertas objeciones que ha recibido en relación a sus dichos acerca de la ausencia, tanto en la cultura griega como en la romana, de una relación del tipo pastor-rebaño.

El comienzo de su respuesta sorprende un tanto, pues señala su reconocimiento de que la idea de la relación pastor-rebaño para dar cuenta de la relación soberano o dirigente político con sus súbditos efectivamente está presente en los griegos. Sin embargo, Foucault va a dividir su respuesta en tres grupos de fuentes principales, que en realidad se encargarán de cuestionar dicha tesis. El primer grupo de ellas hace referencia al vocabulario homérico. De acuerdo a Foucault, la Ilíada y la Odisea presentan una serie de referencias donde se designan al rey como pastor de los pueblos, el poimen laôn, una suerte de apelativo ritual con el que se solía denominar, por ejemplo, a Agamenón. Pero lo cierto es que este 
apelativo sería en efecto sólo de carácter ritual. La literatura indoeuropea, en especial la literatura asiria, dan prueba de ello, sostiene Foucault ${ }^{8}$.

El segundo grupo de textos hace referencia explícita a la tradición pitagórica. En el seudo Arquitas se encuentran alusiones al pastor en determinados temas. Por ejemplo, la etimología tradicionalmente admitida por los pitagóricos refiere nomos, la ley, de nomeus, el pastor. Así encontramos, afirma Foucault, que el pastor es quien hace la ley, dado que se encarga de distribuir el alimento, dirigir el rebaño, indicar la buena dirección; es el que también decide la manera en que las ovejas deben acoplarse a fin de obtener una buena progenie, etc. De allí surgiría el apelativo de Zeus como Nomios, debido a que se trata de un dios pastor, un dios que otorga a sus ovejas el alimento que éstas necesitan ${ }^{9}$. Por otro lado, y siempre dentro de la literatura pitagórica, se encuentra la idea de que el elemento principal del magistrado no es tanto su poder, su fuerza, su capacidad de decisión, sino más bien su capacidad para amar a sus administrados, a los hombres sometidos a él, y a no ser egoísta. El magistrado entendido como un philanthropos, aquél que hace la ley no para él sino para sus administrados. Ahora bien, Foucault sostiene que esta tradición del magistrado entendido como un pastor, si bien se ha conservado durante la Antigüedad, al ser de carácter pitagórico la convierte en poco menos que una tradición marginal ${ }^{10}$. Para sostener esto, Foucault recurre a una tercera serie de textos en la que se destaca el alemán Gruppe, quien en su edición de los fragmentos de Arquitas afirma que la metáfora del pastor no se halla en los griegos, salvo por influencia oriental, y más precisamente hebrea, y cuyos elementos fueron reflejados por los pitagóricos. En contrapartida, Foucault presenta la tesis de Delatte, quien sostiene que el tema del pastor era casi un lugar común entre los griegos, en absoluto patrimonio exclusivo de los pitagóricos. Lamentablemente, según Foucault, Delatte no respalda esta tesis con ninguna referencia específica ${ }^{11}$. Por ejemplo, el Index isokrateon, consultado por Foucault, arroja como resultado la no existencia de referencia alguna a las palabras poimen y nomeus. Si bien en el $A e$ ropagitico Isócrates describe los deberes del magistrado de manera muy similar a la metáfora del pastor, ésta no aparece. Otro tanto sucedería con Demóstenes ${ }^{12}$.

Ahora bien, la gran excepción a esa aparente ausencia es, ni más ni menos, Platón. Éste presenta en una serie de textos al buen magistrado, al magistrado ideal, como un pastor. Básicamente tales referencias se encuentran en Critias, República, Leyes y en especial en Político. Foucault va a bordar en primer lugar los tres primeros textos mencionados, dejando Político para un análisis exhaustivo ulterior.

En primer lugar, Foucault sostiene que la metáfora del pastor presente en los textos platónicos alude al poder pleno y bienaventurado de los dioses sobre la humanidad en los primeros días de su existencia y antes de que la desdicha modificara esa condición. Por aquellos tiempos, los dioses eran los mayorales de la humanidad: alimentaban, guiaban, suministraban principios generales de conducta y velaban por la felicidad y bienestar de los hombres. En segundo lugar, los textos platónicos también hacen referencia al magistrado como pastor, pero esta vez en los tiempos duros, los tiempos actuales, es decir, cuando la humanidad deja de estar presidida por los dioses. Sin embargo, advierte Foucault, ese magistrado nunca es el fundador de la ciudad ni quien le ha dado sus leyes fundamentales. Tan sólo se trata de un magistrado subordinado, cumpliendo una función adyuvante, como ve- 
mos en Político 281d-e. Por último, Foucault se aboca al libro I de la República. Allí encontramos que si bien Trasímaco da por sentado que el buen magistrado es el verdadero pastor, pone en duda que éste tenga en vista esencial y exclusivamente el bien de su rebaño. Para Trasímaco, el pastor se esfuerza sólo en la medida en que puede beneficiarse de su propio rebaño, ya sea en el momento del sacrificio o en el de la venta. La respuesta que recibe es que ése no es el buen pastor ni el verdadero pastor: es sólo su caricatura. Sea como fuere, Foucault sostiene que el pasaje comentado hace referencia, si no a un lugar común entre los griegos (como querría Delatte), sí al menos a un tema muy familiar para Sócrates, Platón y el círculo platónico, que es el tema pitagórico. En efecto, según Foucault, en el libro I de la República aflora el tema pitagórico del magistrado pastor, de la política como pastorado ${ }^{13}$. Y es justamente en Político donde Foucault va a encontrar los argumentos que a su juicio rebatirían cualquier intento por demostrar que Platón defiende la idea del político como pastor de un rebaño.

A grandes rasgos, el desarrollo que hace Foucault de Político es el siguiente. La obra comienza con la pregunta qué es un hombre político. El arte que caracteriza al político es el arte de prescribir, el arte de mandar; quién manda: el rey. Hay dos formas de prescribir: se pueden prescribir las órdenes que uno da y se pueden prescribir las impartidas por otro. Evidentemente, el primer caso es el que corresponde al político. Las órdenes pueden prescribirse sobre cosas inanimadas o sobre seres vivos. El político prescribe órdenes a seres vivos. A su vez, puede prescribir a individuos singulares o bien a animales que viven en grupo. El político prescribe para seres vivos que viven en grupo. Luego, ¿qué es dar órdenes a un grupo de seres vivos, animales u hom- bres? Evidentemente es ser un pastor, Por tanto, en primera instancia, el político es el pastor de los hombres, el pastor de ese tropel de seres vivos que constituyen la población de una ciudad ${ }^{14}$.

Ahora bien, de inmediato surge una objeción en relación al método utilizado: ¿qué significa oponer de ese modo todos los animales, cualquiera sean, a los hombres? No es posible poner a todos los animales de un lado y a los hombres del otro. Es menester realizar divisiones exhaustivas de una y otra parte. Pero esas divisiones se pierden en subdivisiones, y éstas en otras, y no se llega a nada:

«cuando, en esta afirmación, se toma como invariante "magistrado=pastor" — sostiene Foucault - y se varía el objeto al cual se refiere la relación, se pueden hacer todas las clasificaciones que uno quiera de los animales posibles: acuáticos, no acuáticos, pedestres, no pedestres, con patas hendidas, sin patas hendidas, etc., hacer una tipología de los animales $y$, pese a ello, no dar un paso adelante en la cuestión fundamental, a saber: ¿qué es el arte de prescribir?» ${ }^{15}$

En consecuencia, Platón considera conveniente plantearse en qué consiste ser pastor. Ser pastor quiere decir, en primer lugar, ser el único encargado del rebaño. El pastor debe realizar una gran cantidad de cosas: asegurar la alimentación del rebaño, atender a las ovejas más jóvenes, curar a las que están enfermas o lastimadas, etc. En este punto de la discusión, surgen determinados rivales del rey-pastor. El agricultor que alimenta a los hombre y el panadero que hace el pan, por ejemplo, también son pastores del la humanidad; del mismo modo en que los son un médico que atiende a los enfermos, o el maestro de gimnasia o el pedagogo, etc. Para recuperar, entonces, la esencia del pastor - continúa Foucault-, Platón recurre a un mito. En él, se cuenta que el mundo gira sobre sí mismo. En un primer momento, en el sentido 
que es adecuado, el natural, el sentido de la felicidad; cuando éste llega a su fin, viene el movimiento en sentido inverso, el movimiento de los tiempos difíciles. En el primero de los tiempos, la era de Cronos, la humanidad vive en la felicidad. Cada especie de los animales se presenta como un rebaño, a la cabeza del cual está el pastor. Y a la cabeza del rebaño humano está la divinidad. Platón se encarga de aclarar en Político 271c-d, y Foucault lo subraya, que este período no corresponde a la constitución actual del mundo. En este período, la divinidad preside al rebaño humano bienaventurado, abundante en alimentos y perpetuamente renaciente, libre de amenazas y dificultades; lo que le permite vivir sin constitución política, precisamente porque la divinidad preside al rebaño. En cambio, la política y los políticos serán necesarios una vez que el mundo comience a girar en el otro sentido; una vez que los dioses se hayan retirado, dejando a los hombres librados a dirigirse unos a otros:

«pero - aclara Foucault-, y aquí el texto de Platón es muy claro, esos hombres que ahora tienen a su cargo a otros hombres no están por encima del rebaño, así como los dioses podían estar por encima de la humanidad. Ellos mismos son hombres y, por tanto, no se los puede considerar como pastores» ${ }^{16}$.

En reemplazo del modelo del pastor, Platón va a proponer el modelo del tejedor. El arte de la política, así como el arte del tejedor, no se ocupa de todo en general, al modo en que lo hace el pastor con su rebaño. La política, al igual que el arte del tejedor, necesita para desarrollarse una serie de acciones adyuvantes o preparatorias. Así como para que el tejedor pueda trabajar es preciso tundir la lana y trenzar el hilo, una serie artes auxiliares (el arte de la guerra, de la retórica, etc.) debe ayudar al político. La verdadera actividad política consistirá entonces en unir - como el tejedor une la cadena y la trama- los buenos elementos formados por la educación, los diferentes tipos de virtudes opuestas entre sí, como ocurre con los hombres fogosos y los moderados, en la gran lanzadera de la opinión común que los hombres comparten ${ }^{17}$.

«Creo - concluye Foucault - que con este texto tenemos la sensación en debida forma del tema del pastorado. Para Platón, la cuestión no pasa en absoluto por decir que ese tema debe ser eliminado o abolido por completo. Se trata en cambio de mostrar justamente que, si hay pastorado, éste sólo puede darse, a su juicio, en actividades menores, sin duda necesarias para la ciudad, pero subordinadas al orden del político; dichas actividades son, por ejemplo, la del médico, el agricultor, el gimnasta, el pedagogo. Todos ellos pueden, en efecto, compararse con un buen pastor, pero el político con sus tareas particulares y específicas no es un pastor» ${ }^{18}$.

Foucault concluye que la verdadera historia del pastorado comienza con el cristianismo. El pastor se presenta con el cristianismo como un núcleo de un tipo específico de poder sobre los hombres, como una matriz de procedimientos de gobierno de los hombres ${ }^{19}$. Sin embargo, el pastorado cristiano, el que se desarrolla a partir del s. III, en modo alguno, advierte Foucault, es el pastorado hebreo u oriental que hasta aquí hemos caracterizado ${ }^{20}$. La clase del 22 de febrero de 1978 está destinada a mostrar esta diferencia. Por nuestra parte, nos limitaremos tan sólo a lo hecho hasta ahora, pues nuestra intención, como hemos dicho, no es profundizar sobre el pastorado cristiano, sino indagar en la cuestión de si efectivamente la idea del gobierno como pastor no ha estado presente, tal como Foucault afirma, en las culturas griega y romana.

\section{Agamenón y Eneas, pastores subalternos}

No en vano Foucault debió destinar unos minutos de su clase del 15 de febrero de 
1978 para responder a ciertas objeciones a la idea de que una relación del tipo pastor-rebaño no está presente ni en los griegos ni en los romanos. Lamentablemente, las objeciones no nos han llegado; pero las respuestas, o los minutos destinados a responder, nos permitirán ensayar algunas.

Para comenzar, me gustaría abordar la Ilíada a fin de realizar algunas breves comparaciones con los dichos de Foucault. Dijimos que para él unas de las características del poder del pastor era que no se ejercía sobre un territorio sino más bien sobre un «rebaño en movimiento»; paralelamente, que se trataba también de un poder finalista, un poder que guía hacia una meta y que sirve de intermediario hacia ésta. Pues bien, considero que la Ilíada presenta una serie de pasajes donde esto último sucede. Tomemos, por ejemplo, los momentos previos a la partida del ejército griego. En la primera reunión en Áulide, Agamenón se apresta a realizar sacrificios a Zeus y a Apolo; una vez finalizados, se produce un portento que es analizado por Calcante como una señal de Zeus de que Troya iba a ser tomada, aunque antes debían pasar nueve años. El portento se refuerza con un relámpago lanzado por Zeus a manera de aliento para las tropas aqueas ${ }^{21}$. Lo que me interesa subrayar de este pasaje es el hecho de que un Dios, Zeus en este caso, claramente hace las veces de «pastor» que guía a una «rebaño en movimiento», en esta ocasión, hacia Troya. Agamenón hará las veces de pastor subalterno del rebaño, por quien se verá obligado a sacrificar a su propia hija, Ifigenia ${ }^{22}$. El adjetivo poimen laôn podrá ser un apelativo ritual, como Foucault asevera, pero la función del jefe de los aqueos y del dios del Olimpo me parece que trazan líneas muy similares a las que encontramos al caracterizar el poder pastoral. Por otra parte, se pone en cuestión la idea de que los dioses griegos sean dioses «intramu- ros»». Los dioses griegos efectivamente fundan una ciudad, indican su emplazamiento, construyen la muralla, transmiten sus consejos mediante los oráculos, pero también acompañan y guían al rebaño fuera de la ciudad, hacia una meta determinada. La sensación que nos queda de la caracterización de Foucault sobre los dioses griegos es la de unos dioses «regionales»; dioses encerrados en la ciudad que fundan y en la que son venerados. Volviendo a la Ilíada, tal vez el caso más claro contra aquello sea el de la diosa Atenea. Si bien los aqueos creían que una estatua de la diosa en poder de los troyanos era lo que hacia a éstos inexpugnables - y de hecho, según parece, así sucedía-, Apolodoro nos cuenta que fue la misma Atenea la que inspiró a Prilis, hijo de Hermes, la sugestión de que se podía entrar a Troya por medio de un caballo de madera ${ }^{23}$. Estratagema que además contaría con la falsa historia que Sinón les contaría a los troyanos, a fin de inducir a éstos a que ingresaran finalmente el caballo en la ciudad. Y Virgilio, confirmando el favor de Atenea sobre los griegos, pone en boca de Sinón:

«La esperanza de Grecia para el triunfo/estribó siempre en el favor de Palas/Pero dos criminales, el Tridida/y Ulises, concertados para el robo/del sacro Paladion, matan al guardia/del alcázar, y, dueños de la efigie/osan tocar las virginales ínfulas/con sanguinarias manos. Desde entonces, /perdiéndose como agua de menguante/la esperanza y los bríos de los Griegos:/la diosa estaba aira$d a »{ }^{24}$

Y la diosa «estaba airada» porque una de las cualidades de los dioses griegos era su carácter pasional. Lo que quiero decir con ello es que justamente es ese carácter pasional el que Foucault parece pasar por alto en su caracterización de los dioses griegos. Es el carácter pasional el que nos hace descreer de un dios «intramuros», de unos dioses no-finalistas en 
sus acciones, de unos dioses que no guían a sus rebaños en movimiento, llevados justamente por ese carácter pasional que los hace inestables en cuanto a los destinatarios de sus favoritismos, como vimos en el ejemplo de Atenea. Tal vez la caracterización que Foucault realiza de aquellos dioses griegos se ajuste más bien a lo que antes dijimos: divinidades menores que sólo era reconocidas en ciertas regiones, como Pan en Arcadia, y no sin cierta resistencia, en este caso, por cierto ${ }^{25}$; divinidades que tenían un radio de influencia menor; divinidades, en definitiva, «regionales»; muy dispar, en efecto, a la suerte de los principales dioses del Olimpo.

En lo que respecta al mundo romano, me gustaría examinar otra vez un texto que Foucault no menciona: la Eneida. Escrita en el s. I a.C., la obra representa el monumental intento de Virgilio por darle a Roma un origen heroico y mitológico, mediante la combinación de mitología e historia. Inevitables han resultado siempre las comparaciones de los eruditos con la Ilíada y la Odisea. Particularmente, me interesa mencionar algunas consideraciones que Carlos Fernández Corte realiza de Eneas en comparación con Ulises. Del primero, sostiene:

«Deja atrás todo su mundo destruido y debe buscar una nueva patria para su hijo, sus compañeros y sus dioses. Mientras Ulises es un individualista, al que le basta con regresar solo, Eneas es un héroe social. Su meta no tiene sentido si no la alcanza, al mismo tiempo, con los restos de su pueblo [...] Esta entrega en manos del destino, la sumisión a su misión y a la persecución de un ideal hacia el que guía a todo un pueblo facilitaron muy pronto la cristianización de Eneas, que fue visto como un nuevo Abraham» ${ }^{26}$.

En cuanto a la relación de Eneas con los dioses, agrega:

«Nunca le faltan al viaje de Eneas signos del favor divino que le encarecen la trascen- dencia de su empresa y le garantizan que llegará a buen puerto [...] la llegada de Eneas a Italia significa el cumplimiento de la voluntad del Hado y forma parte del plan divino trazado para Roma y su historia» ${ }^{27}$.

Me parece que las consideraciones de Carlos Fernández Corte ayudan a trazar un paralelo cuya primera parte ya hemos visto: Zeus, Agamenón y los aqueos, por un lado, y ahora Júpiter-Apolo, Eneas y su pueblo, por el otro. El dios (Zeus/Júpiter-Apolo) es el pastor, el rey (Agamenón/Eneas) el pastor subalterno y el pueblo (los aqueos/los troyanos) el rebaño. Asimismo, vemos nuevamente que varios dioses, Júpiter y Apolo principalmente, acompañan a su «rebaño en movimiento», al tiempo que ejercen un poder finalista: velan por la llegada y conquista de Roma por parte de los troyanos vencidos por los griegos

«... "Reacios Dardanios, la región primera/que vuestra raza vio brotar aguarda, /ubérrima y feliz, vuestro retorno:/id a buscar a vuestra antigua madre. /Allí dilatará el solar de Eneas/su señorío por el orbe entero/él y en pos de él, los hijos de sus hijos/y cuantos nazcan de su noble alcurnia»/Así habla Febo, y bulliciosa estalla/la alegría común. Inquieren todos/cuál será la ciudad que el dios anuncia/y a que manda volver al pueblo errante..."” ${ }^{28}$.

\section{La edad de Cronos y la edad de Zeus}

El tema del mito en los textos platónicos se torna fundamental a la hora de abordar la cuestión de definir al político-pastor. Como vimos, Foucault hace especial hincapié en la idea de que el político, entendido como pastor del rebaño, pertenece a una época del mundo que no es la actual; una época en la que los dioses gobernaban directamente a los hombres. Antes de entrar de lleno en análisis de Político, me gustaría dar algunas precisiones acerca del tema en Critias, Leyes y también en Político. 
Foucault está en lo cierto cuando asevera que el tema del pastor hace referencia a una época del mundo que los mitos platónicos declaran que no es la actual. Sin embargo, esto es así en Leyes y en Político. El diálogo Critias, en cambio, presenta una variante no menor que me gustaría compartir. Como bien observa Francisco Lisi, si bien la historia de la Atenas originaria esbozada en Critias sigue los principios filosóficos-históricos presentados en el mito de Político (269c274e), el período en el que se enmarcan dichos relatos mitológicos no es el mismo. En este último, al igual que en Leyes IV 713e, el relato se sitúa en la época de Cronos, pero Critias lo sitúa en la época de Zeus (Critias 121b) ${ }^{29}$. La consecuencia inmediata más importante, como señala Lisi, es que el gobierno de la Atenas originaria no estaba dada por los dioses de forma directa sobre los hombres, sino que el gobierno estaba a cargo de los filósofos: «Hefesto y Atenea [...] recibieron ambos esta región como única parcela, apropiada y útil a la virtud y a la inteligencia por naturaleza, implantaron hombres buenos, aborígenes, e introdujeron el orden constitucional en su raciocinio» ${ }^{30}$.Asimismo, de acuerdo con Lisi, existe otro elemento importante que establece la diferencia histórica antes marcada entre los relatos de Político y Leyes, por un lado, y Critias, por el otro:

«el cataclismo que provoca la desaparición de la Atlántida y la Atenas originaria [relatado en Critias] no es universal, como lo muestra la continuidad histórica de Egipto (Timeo 22c-e), en tanto que el descrito en el Político abarca todo el universo y modifica la naturaleza del cosmos (269e-271c). Es esta diversidad de períodos lo que hace necesaria una técnica política - arte no existente bajo el dominio de los dioses - con la consiguiente aparición de la organización estatal y el abandono del comunismo absoluto predicado como la mejor forma de relación social en las Leyes V 739 a-e» ${ }^{31}$.
Lisi concluye su análisis afirmando que la filosofía de la historia platónica reconoce dos ciclos bien diferenciados. En uno de ellos, no hay historia en sentido estricto, ya que bajo la dirección directa del demiurgo el cosmos y el hombre no conocen el devenir desordenado. En tanto, en el otro, se instaura el discurrir histórico que presupone una decadencia y una disgregación paulatina del cosmos y del orden político y humano. Ello se pondría de manifiesto por los cataclismos parciales, que indicarían el progresivo alejamiento del mundo del orden ideal. La historia de la Atlántida y la Atenas primitiva, narrada en Critias, pertenecería al comienzo de dicho período ${ }^{32}$.

Por otra parte, la descripción de la organización política del Imperio de la Atlántida nos muestra que la región estaba dividida en diez partes, cuyos gobiernos estaban a cargo de sus diez reyes respectivos:

«El gobierno y la comunidad de los reyes se regían por las disposiciones de Poseidón tal como se las transmitían la constitución y las leyes escritas por los primeros reyes en una columna de oricalco que se encontraba en el centro de la isla en el templo de Poseidón, donde se reunían bien cada lustro, bien, de manera alternativa, cada seis años, para honrar igualmente lo par y lo impar» ${ }^{33}$.

Si bien el emplazamiento de la Atlántida no ha podido establecerse de manera cierta, algunos han querido ver una intención política en Platón proyectando los rasgos esenciales de la constitución ateniense del pasado en el relato de la Atenas originaria, y por el otro los rasgos de las constituciones lacedemonias o incluso las de Persia contemporánea ${ }^{34}$. Sea como fuere, lo que me interesa destacar es que la descripción política hallada en Critias claramente se encuentra más cercana, temporalmente hablando, a Platón de lo que naturalmente se encuentran los mitos relatados en Leyes y Político. 
Ya no nos encontraríamos en las lejanas épocas de Cronos sino en las de Zeus, las actuales:

«Esta vida, Sócrates, de la que te estoy hablando, era, por cierto, la vida de los hombres de la época de Cronos. En cuanto a aquella que según la tradición corresponde a la época de Zeus, la actual, la conoces por propia experiencia, ya que vives en ella» ${ }^{35}$.

Con ello lo que intento es, si no rebatir, al menos poner en duda ciertas ideas de Foucault respecto de una ausencia de la noción de político como pastor en los griegos, o bien considerarla una idea marginal. Por lo pronto, Critias, más allá de lo que Foucault sostenga, nos presenta los hechos de una manera muy diferente a la que el filósofo francés esgrime.

\section{Platón: el pastor y el tejedor}

El mito en Político divide al texto en dos partes bien diferenciadas. En la primera de ellas, Platón identifica al político como pastor de rebaño. Sin embargo, como hemos visto desde la óptica de Foucault, la definición a la que llega no es satisfactoria. La segunda de las partes, por tanto, va a analizar la idea desde otro punto de vista, que a la postre será la definitiva: el político como tejedor. Particularmente, me interesa abordar el texto comparando los resultados de la segunda parte - esto es, el político como tejedor - con los de la primera - es decir, el político como pastor de rebaño.

Como bien afirma Foucault, la función del pastor, encarnada en las tareas propias del agricultor, el médico, el pedagogo, etc.; cumplirán una función coadyuvante en el Estado, reservando la principal para el magistrado entendido como tejedor ${ }^{36}$. La traducción del texto de Foucault que estamos viendo utiliza la palabra «adyuvante» para traducir el término aitía, que aparece en Político 281d. Santa Cruz, por su parte, traduce el térmi- no del mencionado pasaje platónico como «causa»; reservando el de «concausa» para dar cuenta de sunaítios, presente también en el mismo pasaje antes referenciado ${ }^{37}$. En consecuencia, Político nos dice que las diferentes actividades que en la primera parte competían con el pastor, como el agricultor, el panadero, el médico, etc., son sunaítios, es decir, «concausas» en la organización de un Estado; mientras que el político, entendido como tejedor, sería la aitía, la «causa» principal. Me interesa detenerme en este punto para analizar brevemente qué entiende Platón por «causa» y «concausa», dado que el tema tiene relevantes consecuencias en la esfera política. Platón trata el tema principalmente en tres diálogos: Fedón, Timeo y Filebo. En el primero de ellos, Sócrates examina de buen grado a Anaxágoras en relación a su idea de que la mente ordena y causa todo. Sin embargo, la decepción de Sócrates es grande al encontrar que Anaxágoras en realidad no recurre a la inteligencia para explicar la causalidad de las cosas ${ }^{38}$ :

«Me pareció que había sucedido algo muy parecido a como si uno afirmara que Sócrates hace todo lo que hace con inteligencia, $\mathrm{y}$, luego, al intentar exponer las causas de lo que hago dijera que ahora estoy aquí sentado por esto, porque mi cuerpo está formado por huesos y tendones, y que mis huesos son sólidos y tienen articulaciones que los separan unos de otros [...] Así que al balancearse sus huesos en sus propias coyunturas, los nervios al relajarse y tensarse a su modo hacen que yo sea ahora capaz de flexionar mis piernas, y ésa es la razón por la que estoy aquí sentado con las piernas dobladas» ${ }^{39}$.

Así, pues, Sócrates concluye:

«si uno dijera que sin tener cosas semejantes, es decir, tendones y huesos y todo lo demás que tengo, no sería capaz de hacer lo que decido, diría cosas ciertas. Sin embargo, decir que hago lo que hago a causa de ellas, y eso al actuar con inteligencia, y no por elección de lo mejor, sería un enorme y excesivo abuso de 
expresión. Pues eso es no ser capaz de distinguir que una cosa es lo que es la causa de las cosas y otra aquello sin lo cual la causa no podría nunca ser causa» ${ }^{40}$.

Tanto en Timeo 46c-d, como en Filebo 27a, la idea es similar: la «concausa» es algo diferente de la «causa», sin lo cual ésta no puede actuar. Cuando Platón traslada estas nociones al ámbito político, lo hace del siguiente modo. Así como el arte de tejer tiene artes auxiliares — como por ejemplo, la que produce lanzaderas, o bien el cardador-, en el ámbito político sucede otro tanto. Las artes que en la primera parte competían con el pastor por la primacía en al ámbito político, ofician ahora como ciencias auxiliares, como «concausas» o, como Foucault sostiene, funciones adyuvantes: "a todas aquellas artes que fabrican algún instrumento, pequeño o grande, referido a la ciudad, se las tendrá por concausas: sin ellas jamás podrá existir ni ciudad ni política; sin embargo, a ninguna de ellas las consideramos jamás función del arte real» ${ }^{41}$. Me interesa subrayar este punto: si bien Foucault está en lo cierto al relegar la función del pastor a una tarea coadyuvante o concausa, vemos que sin embargo la tarea real del político no podría llevarse a cabo sin ella. Platón parece ir aún más lejos:

«Quien haya considerado el conjunto de las ciencias de las que hablamos debe reconocer que ninguna de ellas se ha revelado como política. Porque la ciencia que es verdaderamente real no debe actuar por sí misma, sino gobernar a las que tienen la capacidad de actuar, ya que ella, en lo que toca a la oportunidad o inoportunidad, conoce el punto de partida y la puesta en marcha de los más importantes asuntos de la ciudad, mientras que las demás deben hacer los que les ha sido impuesto» ${ }^{42}$.

Esto es, las ciencias auxiliares, las concausas, las funciones coadyuvantes, son las que actúan, en tanto que la políti- ca es la que dirige. En otras palabras, el Estado o la cuidad se organizan en rebaños, pero se los dirige a la manera de un tejedor, es decir, una función que, como el mismo Platón afirma, es más general, más abarcadora que la del pastor. Recordemos que Platón reconoce que la primera caracterización del político como pastor del rebaño humano, a la que le asigna la función de «crianza», es algo que les compete a los otros pastores: agricultor, panadero, médico, etc. La segunda definición, en tanto, intenta darle al político una idea más general de «crianza»: la de «cuidado» 43 .

A todo esto, me interesó destacar el punto anterior en virtud de que se encuentran grandes semejanzas entre la definición de tejedor y la de pastor que ahora quisiera examinar. En pocas palabras, Platón sostiene que sensatez y valentía son partes de la virtud ${ }^{44}$. De allí que la tarea del político consistirá en tejer, combinando trama y urdimbre, los caracteres sensatos con los valientes ${ }^{45}$. Para llevar adelante tal empresa, el político deberá valerse del juego, la educación, la concertación de matrimonios; y en ciertos casos deberá apelar a castigos o al mismo exilio, cuando no a la muerte, para con aquellos de mala naturaleza ${ }^{46}$. Ahora bien, comparemos esta tarea del político con la definición que da Platón del pastor al comienzo del diálogo:

«él [el pastor] es criador de su rebaño, él quien apacienta los bueyes, él su médico; él es, por así decirlo, quien concierta los matrimonios, y para el nacimiento de las crías y el parto de sus madres, es el único entendido en el arte del alumbramiento. Además, sin duda alguna, en lo tocante a los juegos y la música - en la medida en que las crías tienen por su naturaleza parte en ellos-, no hay mejor que él para confrontarlas y amansarlas con ensalmos, ejecutando con instrumentos o sólo con su boca, la mejor música que conviene a su rebaño» ${ }^{47}$. 
Francamente, me resulta difícil, después de leer este pasaje y confrontarlo con la noción de político, no coincidir con Delatte: el tema del pastor, tanto aquí como en los diferentes recorridos que hemos hecho en este trabajo, parece ser un tema tan común que la propia definición del político como tejedor no puede dejarlo de lado; tan común que el pastor es «concausa» del tejedor. Si me tomo de la idea de que entre la administración del Estado y la de una casa no hay diferencia esencial, sino sólo cuantitativa ${ }^{48}$ —idea que Aristóteles critica en Política I, 1, $1252 \mathrm{a}$ - me animaría a afirmar que la diferencia entre el pastor y el tejedor es una diferencia tan sólo cuantitativa: pone de manifiesto la distancia que se observa entre la administración del Estado y la administración de los diferentes grupos específicos que componen una ciudad; entre la administración del conjunto de los distintos rebaños que conforman una población y la administración de un rebaño en particular; en definitiva, entre el político y el agricultor, el panadero, el médico, el pedagogo, etc.

\section{Conclusión}

Desde un primer momento, nuestro objetivo ha sido concreto: analizar la aparente ausencia que Foucault declara de la idea del político como pastor de rebaño tanto en la cultura griega como en la romana. Para ello, comenzamos analizando los preparativos, toma y caída de Troya, así como el comienzo de la Eneida. En ambos casos, encontramos que la idea del dios como pastor, del rey como pastor subalterno y del pueblo como rebaño quedaba representada, en un caso, en las figuras de Zeus, Agamenón y los aqueos; en el otro caso, Júpiter-Apolo, Eneas y los troyanos vencidos. Al mismo tiempo, quisimos poner en cuestión ciertas ideas de Foucault en cuanto a la caracterización de los dioses griegos en relación a la religión hebrea. Y allí encontramos similitudes significativas, como la de un dios o varios dioses que acompañan al rebaño en movimiento; cuestión esta última que Foucault atribuye casi con exclusividad a los hebreos. Más tarde, llegó el turno de analizar a Platón. En primera instancia, la gran excepción a la tesis de Foucault. Sin embargo, rápidamente vimos que ésta no era tal. Podríamos resumir la defensa de Foucault diciendo que éste atribuye toda referencia al político como pastor o bien a la tradición pitagórica, que a su juicio era de carácter marginal entre los griegos, o bien a una época que los mitos platónicos no situarían en los tiempos actuales. Foucault se vale de la trilogía Leyes, Político y Critias para defender esto último. No obstante, vimos que Critias en realidad lo desmiente, proporcionando elementos que nos permiten dudar de que efectivamente la noción del político como pastor de rebaños perteneció a una época anterior a la actual, lejana al momento en que Platón escribe.

Por último, llegamos a Político, obra a la que Foucault le dedicó la mayor parte de sus análisis. Y aquí volvimos a encontrar ciertas dificultades en su tesis. Platón no relega la idea del pastor en favor de la del tejedor; antes bien, la idea del pastor está tan presente que simboliza las diferentes actividades que llevan a cabo el agricultor, el médico, el pedagogo, etc.; actividades todas ellas que son "concausas» de la política. Si ellas no existiesen, el político-tejedor no podría elaborar el entramado social. Las distintas revisiones que realizamos de las definiciones del pastor y el tejedor nos llevaron a pensar que en realidad los términos simbolizan más bien una diferencia cuantitativa que una diferencia esencial. 


\section{NOTAS}

1 Foucault, M., Seguridad, territorio, población. Curso en el Collège de France (1977-1978), trad. de Horacio Pons, México, FCE, 2006, p. 136.

2 Foucault, op. cit., pp. 148-149.

3 Foucault, op. cit., p. 150

4 Foucault, op. cit., p. 151.

5 Foucault, op. cit., p. 152.

6 Foucault, op. cit., p. 154.

7 Foucault, op. cit., p. 158.

8 Foucault, op. cit., p. 162

9 Foucault, op. cit., p. 163.

10 Foucault, op. cit., p. 164.

11 Foucault, op. cit., pp. 164-5.

12 Foucault, op. cit., pp. 165-6.

13 Foucault, op. cit., pp. 166-8.

14 Foucault, op. cit., pp. 168-170

15 Foucault, op. cit., pp. 170-1.

16 Foucault, op. cit., p. 173.

17 Foucault, op. cit., p. 174

18 Foucault, op. cit., p. 175.

19 Foucault, op. cit., p. 176

20 Foucault, op. cit., p. 192.

21 Ilíada, II, 303-53 (sigo la traducción de Crespo Güemes, E., Madrid, Planeta, 2000).

22 Cfr. Eurípides, Ifigenia en Áulide.

23 Cfr. Apolodoro, Epitome v. 14, en Graves, R., Los mitos griegos II, Buenos Aires, Alianza, 1993, pp. 413-427.

24 Eneida, II, vv. 162-170, la bastardilla es nuestra. La traducción que cito corresponde a la que Aurelio Espinosa Pólit (Eneida. Edición de Fernández Corte, C., Barcelona, Altaya, 1993) vertió en endecasílabos. Sin embargo, la numeración de los versos que refiero corresponde a los hexámetros latinos del original.
25 Cfr. Graves, R., op. cit., I, pp. 122-5.

${ }^{26}$ Cfr. Fernández Corte, C. (editor), Eneida de Virgilio, Barcelona, Altaza, 1994. Introducción, p. 54.

27 Cfr. Fernández Corte, C. (editor), op. cit., p. 77.

28 Cfr. Eneida, III, 94-101.

29 Cfr. Lisi, F. (traductor), Critias de Platón. En Diálogos VI, Madrid, Gredos, 2000, Introducción pp. 262-264.

30 Critias $109 \mathrm{c}-\mathrm{d}$. La bastardilla es nuestra.

31 Cfr. Lisi, F., op. cit., p. 263.

32 Cfr. Lisi, F., op. cit., pp. 263-264.

33 Cfr. Critias, $119 \mathrm{c}-\mathrm{d}$.

34 Cfr. Lisi, F., op. cit., p. 259.

35 Político 272b. La bastardilla es nuestra (sigo la traducción de Santa Cruz. M. I., Madrid, Gredos, 2000).

36 Foucault, op. cit., p. 167.

37 Santa Cruz, M. I. (traductora), Político de Platón, en Diálogos V, Madrid, Gredos, 2000.

$38 \mathrm{Cfr}$. Hemos resumido y comentado Fedón, 97d-98c.

39 Cfr. Fedón, 98c-d (sigo la traducción de García Gual, C., Madrid, Gredos, 1992).

40 Cfr. Fedón, 99a-b. La bastardilla es nuestra.

41 Cfr. Político 287c-d. La bastardilla es nuestra.

42 Cfr. Político 305c-d. La bastardilla es nuestra.

43 Cfr. Politico 276c-e.

44 Cfr. Político 306b.

45 Cfr. Político 311b-c.

46 Cfr. Político 308e-311c

47 Cfr. Político 268a-b. La bastadilla es nuestra.

48 Cfr. Político 259b. 